\title{
Tsunami due to the 2004 September 5th off the Kii peninsula earthquake, Japan, recorded by a new GPS buoy
}

\author{
Teruyuki Kato ${ }^{1}$, Yukihiro Terada ${ }^{2}$, Keiji Ito $^{2}$, Ryuji Hattori² ${ }^{2}$ Takenori Abe $^{2}$, Toshihide Miyake ${ }^{2}$, \\ Shun'ichi Koshimura ${ }^{3}$, and Toshihiko Nagai ${ }^{4}$ \\ ${ }^{1}$ Earthquake Research Institute, the University of Tokyo, Japan \\ ${ }^{2}$ Technical Research Institute, Hitachi Zosen Co. Ltd., Japan \\ ${ }^{3}$ Disaster Reduction and Human Renovation Inst., Japan \\ ${ }^{4}$ Port and Airport Research Institute, Japan
}

(Received December 20, 2004; Revised April 5, 2005; Accepted April 6, 2005)

\begin{abstract}
A tsunami due to the 2004 M7.4 September 5th earthquake off of the Kii peninsula, Japan, was recorded at the GPS buoy newly designed and established in April 2004, about $13 \mathrm{~km}$ off of the Muroto Promontory, southwestern Japan. The tsunami arrived at the buoy about 8 minutes before its arrival to the nearest tide gauge station at the tip of the Muroto Promontory. The predicted tsunami record based on preliminary source model shows excellent agreement $(\mathrm{rms} 2.7 \mathrm{~cm}$ ) with the observed GPS record. This demonstrates that GPS buoy observations can be used not only for a tsunami warning system, but also for precise determination of the tsunami source.
\end{abstract}

Key words: The 2004 off of the Kii peninsula earthquake, GPS buoy, Tsunami.

\section{Introduction}

Two successive earthquakes of M7.1 (foreshock) and M7.4 (main shock) occurred off of Kii Peninsula, Japan, on September 5th, 2004. They generated significant tsunamis along the southern coast of Japan. According to Japan Meteorological Agency (JMA, 2004), the maximum tsunami height due to the main shock reached $0.9 \mathrm{~m}$ at Kozushima tide gauge station and created significant hazards at ports along the southern coast of Japan (Fig. 1). The maximum run-up height of the tsunami due to the main shock registered $4.6 \mathrm{~m}$ at Kiho-cho, Mie (Koike et al., 2005).

Offshore of southwestern Japan are the areas of repeated historical large interplate earthquakes named as Nankai and Tonankai earthquakes, of which the 1944 Tonankai (M8.1) and 1946 Nankai (M8.0) earthquakes are the most recent. These earthquakes caused tremendous hazards due to tsunamis as well as due to ground shaking. Governmental investigation suggests a $40-50 \%$ probability that the next earthquake of the same type will occur within 30 years. Therefore, it is important to establish an effective countermeasure for the tsunami hazard, in order to protect the local population.

One such system may be real-time monitoring of changes in sea-surface heights. A number of tsunami monitoring systems have been developed. Gonzalez et al. (1999) for example used ocean bottom pressure gauges, with data transmitted through satellites. In Japan, ocean bottom pressure gauge data are transmitted through ocean bottom cables (e.g., Hino et al., 1998).

Copy right(c) The Society of Geomagnetism and Earth, Planetary and Space Sciences (SGEPSS); The Seismological Society of Japan; The Volcanological Society of Japan; The Geodetic Society of Japan; The Japanese Society for Planetary Sciences; TERRAPUB
If the buoy is set offshore distant enough and the data are transmitted in a real-time manner, detection of the tsunami can be used for disaster mitigation. We have developed a GPS buoy for this purpose. We have operated a GPS buoy system offshore Ofunato, northeastern Japan, for about three years and have succeeded to detect two tsunami events; 2001 Peru earthquake and 2003 Tokachi-Oki earthquake (Kato et al., 2001). The present article introduces a newly designed GPS buoy, deployed offshore of the Muroto Promontory, which detected the tsunami generated by the September 5, 2004 earthquake.

\section{A New GPS Buoy System}

We have developed a tsunami monitoring system, which uses Real-Time Kinematic (RTK) GPS technology to position a GPS receiver mounted on top of a buoy floating at the sea surface, relative to a land-based GPS receiver. The data are transmitted from buoy to shore using radio transmission. The GPS phase data are processed on a PC placed at the land-based station (Fig. 2). The newly designed system is similar to that used offshore Ofunato (e.g., Kato et al., 2001). However, considering more practical application to tsunami disaster mitigation, it is designed to survive for more harsh oceanic environments far offshore than the case of Ofunato. Design of the buoy is shown in Fig. 3. Total height is more than $15 \mathrm{~m}$; height above the sea surface is $6.9 \mathrm{~m}$ and the weight is $17 \mathrm{ton}$. The buoy is tethered to the bottom anchor, weighing about 150 tons, by an iron chain.

The data are acquired on board the buoy at a one-second sampling interval and are transmitted in real time by radio to the ground base. The base station is placed in the field of the Muroto Meteorological station, Japan Meteorological Agency. The ground base also has a GPS in- 


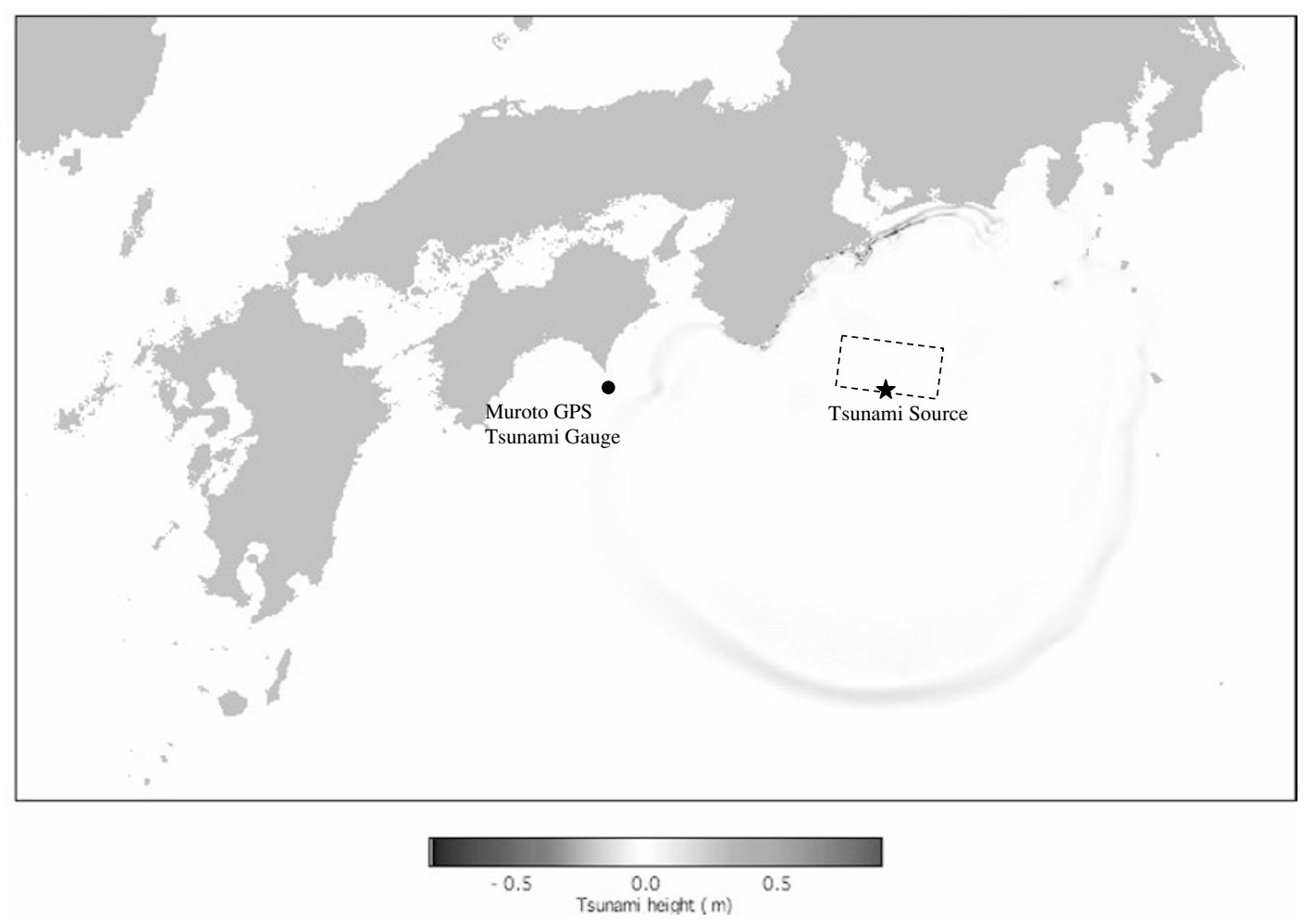

Fig. 1. Location of the 2004 September 5th off the Kii peninsula earthquake and GPS buoy, southwestern Japan.

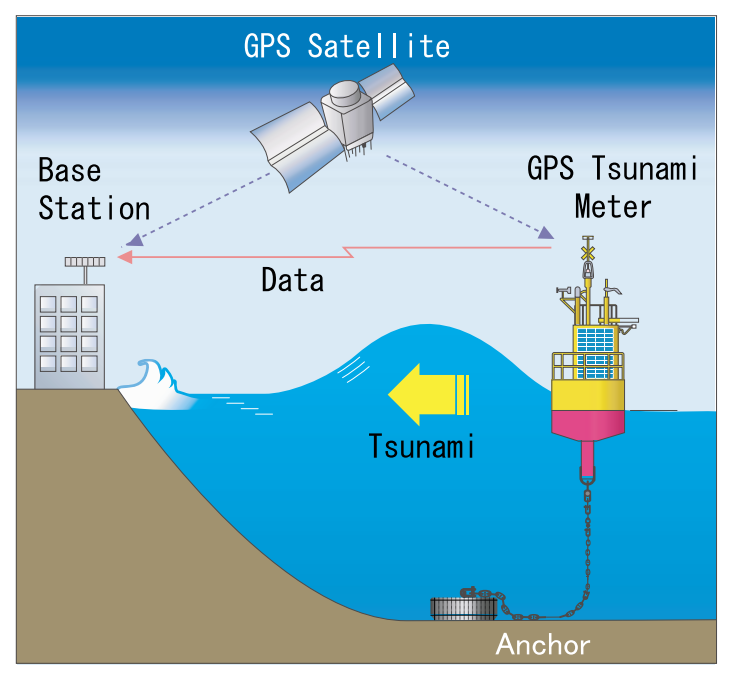

Fig. 2. Plan of GPS tsunami monitoring system.

strument and RTK processing is done at the ground base. RTK-processed positions of the buoy are first applied by a low-pass filtering using a simple moving average technique and are then forwarded to a web server for real-time monitoring of the change of sea-surface using VPN (Virtual Private Network) technology. Latency due to such processing mostly comes from the length of data used for filtering. If we use 60 seconds of moving average, observer should wait at least 30 seconds to get the filtered position. Due to some other technical limitations, the web page is redrawn every 30 seconds. As a result, anyone can view the sea surface with about a 30 -second delay at the web page (http://www.tsunamigps.com/).

The buoy and other equipment were deployed in the middle of April 2004 at about $12 \mathrm{~km}$ nearly south from the tip of the Muroto Promontory, Shikoku, southwestern Japan. The water depth of the site is about $95 \mathrm{~m}$ (Fig. 4). The position of the anchor is (33:08:25.748N, 134:12:10.166E) in WGS84. The baseline length to the base at the Muroto Meteorological Observatory is about $12.6 \mathrm{~km}$.

After some tests, the buoy system became operational in May 2004. Since then, there have been anomalously many typhoons that hit the Japanese islands in the summer of 2004, which have been excellent for testing sustainability of the system. The system survived those typhoons with maximum peak-to-peak wave heights of more than 20 meters.

\section{Tsunami Detected for the 2004 Off Kii Penin- sula Earthquake}

The 2004 Off Kii Peninsula earthquakes (M7.1 and 7.4) occurred at 19:07:7.5 (Japan Standard Time, +9 GMT; $33^{\circ} 1.7^{\prime} \mathrm{N}, 136^{\circ} 48.0^{\prime} \mathrm{E}$, depth $38 \mathrm{~km}$ ) and at 23:57:16.9 (JST; $33^{\circ} 8.6^{\prime} \mathrm{N}, 137^{\circ} 8.5^{\prime} \mathrm{E}$, depth $44 \mathrm{~km}$ ), respectively (Fig. 1). Both of earthquakes generated marked tsunamis.

Figure 5 shows the original record of sea surface height for that day. Since the sea water was rather rough and the peak-to-peak amplitude of wind waves were several meters high.

We applied low-pass filtering to extract the long-period waves, including the tsunami. Figure 6 shows the filtered record for the period from 18:30 to 20:30 that should include the tsunami for the foreshock. Two types of filtering were applied; 150-1800 sec digital band-pass filter and 150 


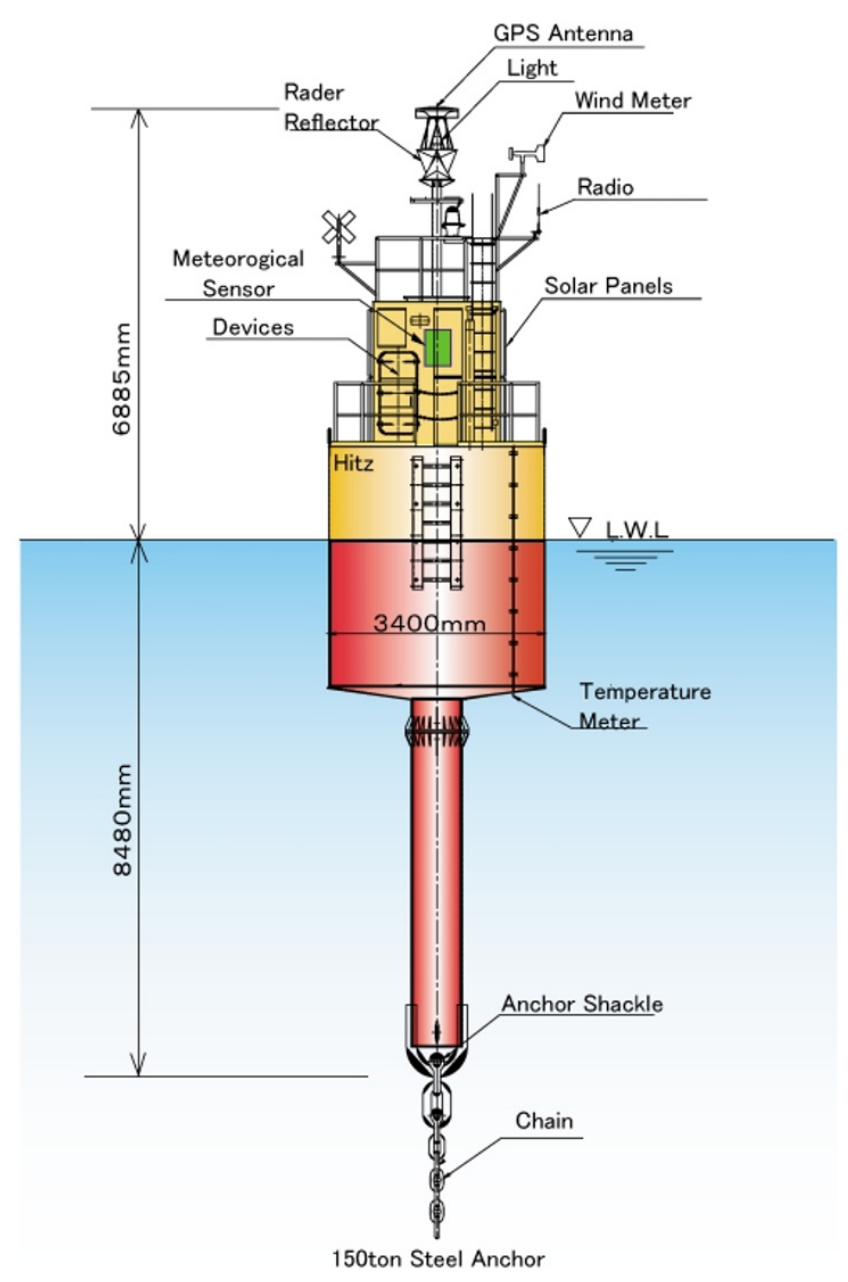

Fig. 3. Design of GPS buoy.

sec moving average after removing the astronomical tides (Matsumoto et al., 2000). The tsunami should have arrived at the buoy around 19:30. However, a significant tsunami cannot be seen in the record, though a possible characteristic wave could be seen around 7:30 (see Satake et al., 2005).

The main shock generated the largest tsunami of this earthquake sequence. Figure 7 is the comparison of the time series for the period of $00 \mathrm{~h}$ to $02 \mathrm{~h}$ (JST) of September 6 , 2004. The uppermost record is the tide gauge record taken at Muroto Port, about $15 \mathrm{~km}$ north of the GPS buoy (Fig. 1). Since the amplitude of tsunami is much exaggerated when it approaches the coast, the tide gauge record is multiplied by $1 / 5$. The second time series of Fig. 7 is the predicted record at the GPS buoy. Source parameter of Yamanaka (2004) was used for this purpose. The third time series is the position record of the GPS buoy after astronomical tides were removed and a moving average of 150 seconds was applied. Matsumoto et al. (2000) was used for estimating astronomical tides. The bottom time series is the same record but after a 150-1800-second band-pass filter was applied.

The filtered GPS position record closely resembles the predicted record, with a rms of $2.7 \mathrm{~cm}$ if we take the first 30 minutes from the onset of tsunami, indicating that the GPS buoy is capable of detecting this size of tsunami. Peak-to-peak amplitude of the largest wave is about $20 \mathrm{~cm}$.
Although numerical simulation suggests a small retarding phase at around 0:25 JST, it cannot be discerned in the GPS record. The first tsunami wave measured at 00:32 at the buoy reached the Muroto tide gauge about 10 minutes later.

\section{Discussion}

Most striking in the record (Fig. 7) is the similarity between the observed and predicted record of the tsunami. Non-linear effects that may prevail in shallow water might be negligible at the ocean depth of this buoy (about $100 \mathrm{~m}$ ). Also, effects of coarse grid for approximating the coast line geometry may also degrade the prediction if the site is too close to the coast (not the case here). Hence, GPS records in the deep outer ocean far from the coast may be helpful for estimating the source effects more directly for numerical simulation studies compared with tide gauge records (Matsumoto and Mikada, 2005; Baba et al., 2005; Satake et al., 2005). The similarity of the simulated and observed records suggest that the accuracy of RTK GPS is enough to detect a tsunami wave of several $\mathrm{cm}$ or greater amplitude.

There are several questions to be raised as to the effective use of GPS buoys for disaster mitigation. First, it should be examined if $13 \mathrm{~km}$ offshore is far enough for early detection of tsunami. As was indicated above, tsunami detection at the GPS buoy preceded by about 8 minutes detection at the Muroto tide gauge. This may be rather marginal for the residents who are living at the tip of Muroto Peninsula. Residents may require much earlier warning, say $20 \mathrm{~min}-$ utes or more would be necessary for effective evacuation. For a more effective system, the buoy may have to be placed much farther from the coast, say more than $50 \mathrm{~km}$. It should be noted, however, that the present location may be effective enough for the people who are living in locations at greater distances, such as Kochi or Osaka, Kobe area.

Data latency in the present system is about 30 second at maximum due both to low-pass filtering and technical limitation in web operation. This is far shorter than the expected lead time of 8 to 10 minutes of early detection of tsunami in the present case. Therefore, the impact of data latency would be negligible even in the present system.

There are advantages and disadvantages to locating the buoy farther from the coast. Since, generally, the water depth is much larger if you go farther from the coast. Then the tsunami amplitudes become much smaller and more difficult to detect. Also, tethering would be problematical in deeper ocean for the depth more than $1000 \mathrm{~m}$. Also, we would need to improve the accuracy of RTK-GPS positioning, particularly the vertical component in case of longer baselines.

There are some other challenging technologies for the outer ocean, such as real-time continuous data transmission, long-term sustainability of the buoy itself. Satellite data transmission shall be investigated for data transmission. For a long-term operation of the buoy system, say 10 years or more, a secure and autonomous buoy system will have to be designed.

In the course of revising this article, a giant earthquake of M9.3 occurred offshore Sumatra Island, Indonesia, and devastated the whole area surrounding the Indian Ocean. An enormous tsunami generated by the earthquake caused 


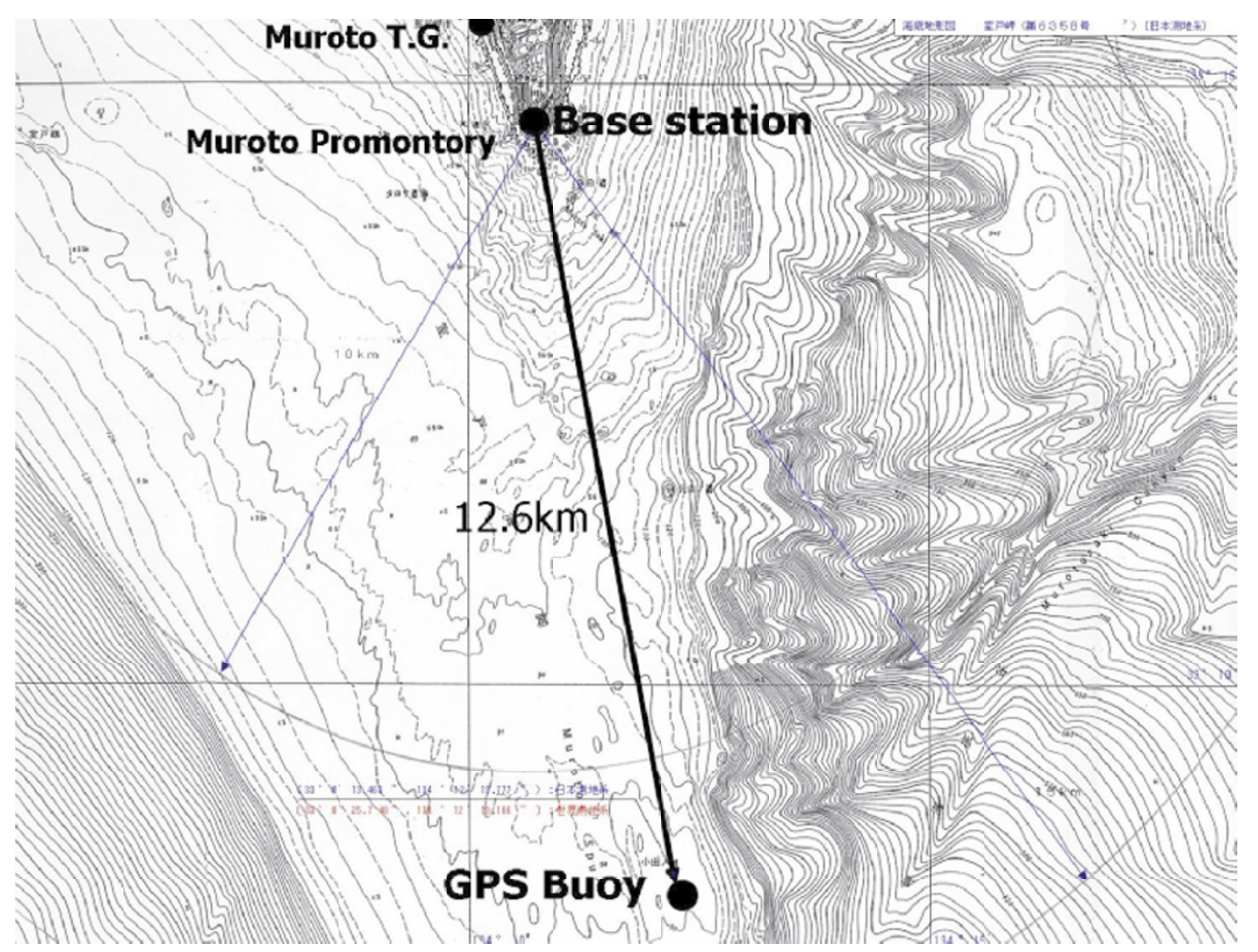

Fig. 4. Ocean bottom topography and the position of the GPS buoy. Topography map was taken from Division of Marine Information, Japan Coast Guard.

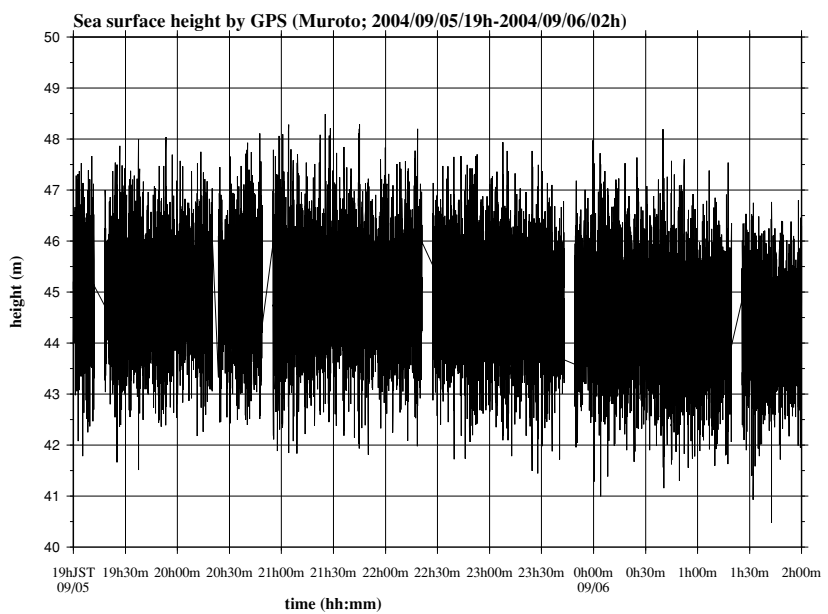

Fig. 5. Original record of sea surface height taken by GPS buoy. Vertical axis is ellipsoidal height in WGS84.

more than 300,000 people of deaths and missing in the area. Many of countries as well as United Nation asserted necessity of implementing a tsunami early warning system in the Indian Ocean as has been operational in the Pacific Ocean. The present system of GPS buoy would be one of powerful tools for monitoring sea-surface and detecting tsunami before its arrival to the coast.

The GPS buoy is much inexpensive compared with the ocean bottom pressure gauge with cable as has been introduced surrounding Japanese Islands. Array deployments of GPS buoys may contribute to reduce costs. On the other

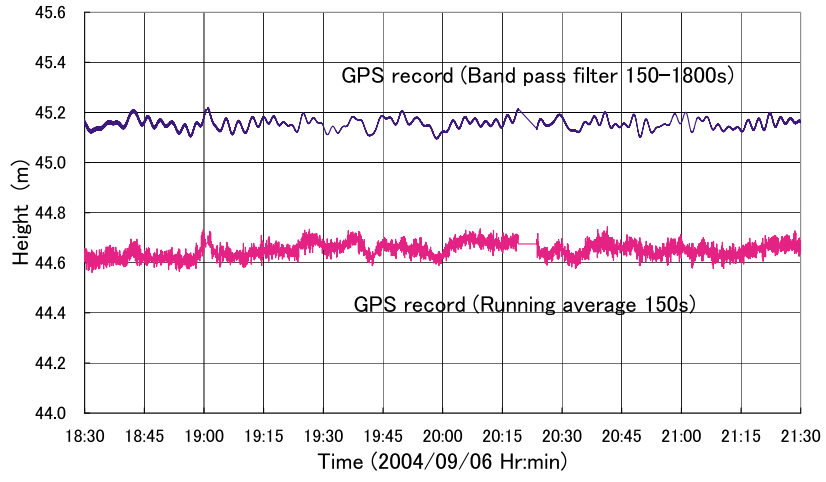

Fig. 6. Filtered vertical components of GPS record for the period 18:30 to 21:30. (Above) 150-1800 second band-pass filtered, and (Bottom) 150 -second moving averaging applied. Vertical position of bottom record is arbitrarily offset for the sake of easy comparison.

hand, current accuracy of RTK-GPS is still inferior to pressure sensor if the distance from the ground base exceeds 20 or $30 \mathrm{~km}$. Combination of GPS buoy with ocean bottom sensors would be an ideal combination for the most effective monitoring system of sea surface.

\section{Conclusion}

A newly designed GPS tsunami monitoring system was established about $13 \mathrm{~km}$ south of the tip of Muroto Promontory. The system was able to detect the tsunami that was generated by the main shock of the 2004 Kii Peninsula earthquake. The maximum peak-to-peak amplitude of the tsunami was about $20 \mathrm{~cm}$ and was consistent with numeri- 


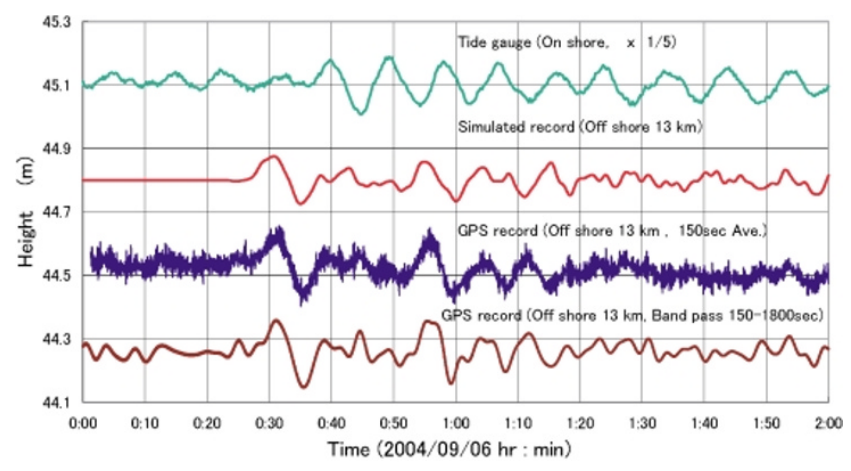

Fig. 7. Comparison of tsunami records for the period 0:00 to 2:00 of September 6th, 2004. (Uppermost) Tide gauge record at Muroto Port; (Second uppermost) Predicted record at GPS buoy; (Third uppermost) Vertical component of GPS record detrended and 150 -sec moving average applied; (Lowest) GPS record after band-passed for 150-1800 seconds. Arbitrary offsets for the vertical position records are given for the sake of easy comparison, except the third record from above.

cal prediction. The arrival of the first maximum wave was about 8 minutes prior to the arrival to the Muroto tide gauge located at the tip of the Promontory. Although deployment farther away from the coast would be ideal, the present system may be served as a powerful tool for monitoring tsunami as a part of the countermeasure for tsunami disaster mitigation.

Acknowledgments. Mr. Sakai of Kochi Prefecture and Mr. Takei, the Mayor of Muroto City, helped the authors for establishing and operation of the GPS tsunami monitoring system. Muroto Meteorological Station kindly permitted us to use their facility as the base station of the system. Reviews by Dr. Yehuda Bock and Dr. Michael A. Fisher helped the authors to improve the manuscript.

Development of the system was supported by the grant of the
Ministry of Education, Culture, Sports, Science and Technology (2002-2004).

\section{References}

Baba, T., P. R. Cummins, and T. Hori, Compound fault rupture during the 2004 off the Kii Peninsula earthquake (M7.4) inferred from highly resolved coseismic sea-surface deformation, Earth Planets Space, 57, 162-172, 2005.

Gonzalez, F. I., E. N. Bernard, H. B. Milburn, and H. O. Mofjeld, Early detection and real-time reporting of deep-ocean tsunamis, Abstracts of IUGG99 in Birmingham, B.127, 1999.

Hino, R., T. Kanazawa, S. Sakai, Y. Tanioka, and K. Suyehiro, Tsunamis from an off-Sanriku and the Papua New Guinea earthquakes observed by ocean bottom tsunami measurement, Programme and Abstracts The Seismological Society of Japan, 1998, Fall Meeting P23, 1998 (in Japanese)

Kato, T., Y. Terada, M. Kinoshita, H. Kakimoto, H. Issiki, T. Moriguchi, M. Takada, T. Tanno, M. Kanzaki, and J. Johnson, A new tsunami monitoring system using RTK-GPS, in Proceedings of the International Tsunami Symposium 2001, Session 5, Number 5-12, 645-651, 2001.

Koike, N., T. Takahashi, K. Imai, Y. Tanioka, Y. Nishimura, K. Harada, S. Suzuki, K. Fujima, Y. Shigihara, Y. Namegaya, and S. Koshimura, Tsunami run-up heights of the 2004 off the Kii peninsula earthquakes, Earth Planets Space, 57, 157-160, 2005.

Matsumoto, H. and H. Mikada, Fault geometry of the 2004 off the Kii peninsula earthquake inferred from offshore pressure waveforms, Earth Planets Space, 57, 161-166, 2005.

Matsumoto, K., T. Takanezawa, and M. Ooe, Ocean tide models developed by assimilating TOPEX/POSEIDON altimeter data into hydrodynamical model: A global model and a regional model around Japan, Journal of Oceanography, 56, 567-581, 2000.

Satake, K., T. Baba, K. Hirata, S. Iwasaki, T. Kato, S. Koshimura, J. Takenaka, and Y. Terada, Tsunami source of the 2004 off the Kii Peninsula earthquakes inferred from offshore tsunami and coastal tide gauges, Earth Planets Space, 57, 173-178, 2005.

Yamanaka, Y., ERI Seismological Note: No. 152 (http://www.eri.u-tokyo. ac.jp/sanchu/Seismo_Note/2004/EIC152e.html), 2004.

T. Kato (e-mail: teru@eri.u-tokyo.ac.jp), Y. Terada, K. Ito, R. Hattori, T. Abe, T. Miyake, S. Koshimura, and T. Nagai 